Review Article

\title{
Setting Evidence-Based Occupational Exposure Limits for Manganese
}

Ruth Bevan ${ }^{\mathrm{a} 1}$, Lini Ashdown ${ }^{\mathrm{b}}$, Doreen McGoughc, Alicia -Huici Montagaud ${ }^{\mathrm{d}}$, Leonard Levy ${ }^{\mathrm{e}}$

${ }^{\mathrm{a} C}$ Cranfield University (Visiting Fellow)

School of Energy, Environment and Agrifood

College Lane

Cranfield

Bedfordshire

MK43 OAL

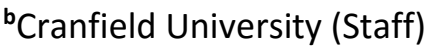

Address as above

'The International Manganese Institute (IMnI),

17 rue Duphot,

75001,

Paris,

France

${ }^{d}$ Centro Nacional de Condiciones de Trabajo

Instituto Nacional de Seguridad e Higiene en el Trabajo

Dulcet, 2-10

E-08034-Barcelona-España

e Cranfield University (Emeritus Professor)

Address as above

${ }^{1}$ Corresponding author contact details:

Dr Ruth Bevan

No.4 The Lodge Business Centre

Rectory Farm

Marston Trussell

Market Harborough

Leicestershire, UK

LE16 9TU

Email: ruth@iehconsulting.co.uk

Tel: +447769264410 


\section{Abstract}

2 In 2004, a review by the Institute of Environment and Health (IEH) made recommendations

3 on occupational exposure limits (OELs) for manganese and its inorganic compounds for

4 inhalable and respirable fractions respectively. These OELs were based on a detailed

5 comprehensive evaluation of all the scientific data available at that time. Since then, more

6 published studies have become available and a number of occupational standard-setting

7 committees (EU SCOEL, US ACGIH-TLV, and Germany MAK) have proposed OEL's for

8 manganese and its inorganic compounds that are somewhat lower that those proposed in the

92004 review.

11 Based on current understanding, the key toxicological and human health issues that are likely to influence a health-based recommendation relate to: neurotoxicology; reproductive and developmental toxicology; and mutagenicity/carcinogenicity. Of these, it is generally considered that neurotoxicity presents the most sensitive endpoint. As such, many of the studies that have been reported since the IEH review have sought to use those neurofunctional tests that appear to be particularly sensitive at identifying the subtle neurological changes thought to associate with manganese toxicity. These recent studies have, however, continued to be limited to a significant extent by reliance on cross-sectional designs and also by use of unreliable exposure estimation methods. Consequently the strength of the potential association between manganese exposure and these subtle subclinical cognitive or neuromotor changes is still poorly characterised and the relevance of these minor differences in terms of either their clinical or quality of life consequences remains unknown. 
25 Based upon the overall evidence, it is concluded that the 8-hr time weighted averages (TWA) 26 for respirable $\left(0.05 \mathrm{mg} / \mathrm{m}^{3}\right.$ as $\left.\mathrm{Mn}\right)$ and inhalable $\left(0.2 \mathrm{mg} / \mathrm{m}^{3}\right.$ as $\left.\mathrm{Mn}\right)$ fractions as 27 recommended by the SCOEL in 2011 are the most methodologically-sound, as they are based 28 on the best available studies, most suited to the development of health-based OELs for both respirable and inhalable fractions. The dose-response characterisation informed by the examined studies used can be considered to establish a true human NOAEL for all the neurofunctional endpoints examined within the selected studies.

\section{Keywords}




\section{Introduction}

The purpose of this paper is to review and describe the development of contemporary recommended or set occupational exposure limits (OEL) for manganese and its inorganic compounds by a number of authorative OEL-setting bodies in Europe and the USA. The process, as will be shown, is complex as the most informative studies are those using groups of exposed workers who have been exposed to a range of different manganese compounds of differing solubility and particle size and measured by different sampling metrics (respirable, inhalable and total). Unfortunately, airborne exposure of workers cannot reliably be validated by biological monitoring as, due to the homeostatic control of manganese by the liver, there is no clear correlation between long-term exposure to manganese and its inorganic compounds and the biological monitoring of manganese in the urine or blood (Zheng et al. 2011; Laohaudomchok et al., 2011; Gil et al., 2011). To add to this complexity, none of the worker studies of the subtle neurofunctional (cognitive and motor) effects reported have used the same battery of tests with a standardised protocol. This makes comparison of the studies somewhat problematical.

\section{Overview of OEL setting}

Occupational Exposure Limits (OELs) have now been a feature of the industrialised world for many decades. The objective of OELs is to set limits for exposure via the airborne route such that exposure, even when repeated on a regular basis throughout a working life, will not lead to adverse effects on the health of exposed persons and/or their progeny at any time (as far as can be predicted from the contemporary state of knowledge). OELs may be established using human and/or animal data and are intended to be protective under realistic workplace 
exposure conditions (e.g. by mandating controls on the maximum exposure during a working day or on peak short-term exposures) (EC, 2013). The EU Scientific Committee on Occupational exposure Limits (SCOEL) advises that OELs may principally be used 'to provide standards or criteria against which measured exposure levels in existing workplaces may be compared in order to ensure that, as far as the current state of knowledge permits, control is adequate to protect health'. However, OELs can also be used for designing new plants and processes to ensure that they 'are engineered in such a way that exposures can be controlled at levels which will not damage health' (EC, 2013). In general OELs are used by risk managers to ensure that workers are not exposed to substances above the OEL whether it is an 8-hr TWA or 15min STEL. This often results in exposures well under the OEL (guideline or statutory).

Various but similar approaches exist for setting OELs and, depending on the particular socioeconomic, legislative and political environment, different regulatory bodies (e.g. SCOEL ${ }^{1}$ in the EU, MAK ${ }^{2}$ in Germany and the American Conference of Governmental Hygienists ${ }^{3}$ (ACGIH) in the US) may reach somewhat differing conclusions as to what constitutes the appropriate OEL for a substance.

\subsection{Health based vs. risk based OELS}

\footnotetext{
${ }^{1} \mathrm{http} / /$ ec.europa.eu/social/main.jsp?catId=148\&intPageId=684\&langId=en

${ }^{2} \mathrm{http}: / / \mathrm{www} . d f g . d e / e n / d f g \_p r o f i l e /$ statutory_bodies/senate/health_hazards/

${ }^{3} \mathrm{http} / / / \mathrm{ww} w$.acgih.org/tlv-bei-guidelines/policies-procedures-presentations/overview
} 
Health based OELs: these are established where the available scientific data base leads to the conclusion that it is possible to identify a clear threshold dose/exposure level below which exposure is not expected to lead to adverse effects (EC, 2013). These OELs do not take into account socioeconomic or achievability factors.

Risk-based OELs: these are established when it is not possible on present knowledge to define a threshold of activity (e.g. genotoxicity, carcinogenicity and respiratory sensitisation) it must be assumed that any level of exposure, however small, might carry some finite risk (EC, 2013). In the EU it is the responsibility of the Commission to set 'risk-based' OELs, which requires consultation with interested parties (EC, 2013). Alternatively, a health-based limit could be set but socioeconomic and/or achievability are taken into account. In practical terms, this means that the available data would allow the establishment of a health-based limit but, the stakeholders (government, trade unions and industry) may negotiate to establish an OEL above the concentrations(s) of the health-based limit due to socioeconomic or practical reasons.

\subsubsection{General procedure for setting health-based OELs}

For chemicals where a threshold of adverse health effect (immediate or delayed) has been identified from good quality human and experimental studies, OELs are established by application of an uncertainty factor (Dankovic et al., 2015) to a point of departure (e.g. $N(O) A E L, L(O) A E L$ or $B M D)$ for the most sensitive adverse health effect in this case neurotoxicity. Expert judgement is usually needed by these OEL-setting committees on a caseby-case basis to determine an appropriate uncertainty factor. OELs are established in relation 
to a reference period of $\mathbf{8}$ hours, for a $\mathbf{4 0}$-hour working week and for a working lifetime (8hour TWA $\mathrm{AEL}^{4}$ and expressed as $\mathrm{ppm}$ or $\mathrm{mg} / \mathrm{m}^{3}$.

For some threshold chemicals, compliance with an 8-hour TWA does not adequately control the adverse health effects, and short-term exposure limits (15 min. STELs) are set. This is likely to arise for substances for which a critical effect is observed following a brief exposure (e.g. CNS depression) and where the 8-hour TWA OEL is established at a level not very much lower than exposures at which there might be a risk of short-term effects occurring.

In addition, for chemicals where biological monitoring data is available, biological limit values (BLVs) can be set. These define levels of substances in humans, their metabolite, or indicator of effect e.g. in blood, urine or breath in workers exposed to the chemical in question at the level of the OEL. Although biomonitoring provides information about total exposure from all routes (inhalation, ingestion and dermal), in an occupational setting inhalation is most likely to be the predominant route of exposure, particularly when considering $\mathrm{Mn}$ industries. . BLVs do not indicate a sharp distinction between hazardous and non-hazardous exposures. For many substances, the data are too limited to support a biological monitoring method, or a metabolite or indicator cannot be defined.

\footnotetext{
${ }^{4}$ TWA - time weighted average for the exposure to a chemical can be used when both the chemical concentration and time for exposure varies. For gases the units are in parts per million $(\mathrm{ppm})$ and for particulates such as dust, smoke and mist, units are in milligrams per cubic meter $\left(\mathrm{mg} / \mathrm{m}^{3}\right)$.
} 
Where data is inadequate to set a BLV, a biological guidance value (BGV) can be established. This refers to the upper concentration of the substance (or a metabolite) in biological medium corresponding to a certain percentile (generally 90th or 95th percentile) in a defined reference population. These values can be helpful in identifying where risk management measures may be introduced to reduce exposure.

\subsubsection{OEL procedure for non-threshold chemicals}

There is growing recognition that carcinogenic risk extrapolation to low doses (and standard setting) must consider the mode of action of a given chemical. To date there is a general agreement to distinguish between genotoxic and non-genotoxic chemicals, but further differentiation based on mode of action also seems appropriate (Bolt \& Huici-Montagud, 2008). This means that a threshold approach may be applied for some carcinogens. In the EU, SCOEL distinguishes 4 types of carcinogen on mechanistic grounds, namely:

Group A: Non-threshold genotoxic carcinogens - for low-dose risk assessment linear nonthreshold (LNT) modelling is applied;

Group B: Genotoxic carcinogens - where a threshold cannot be sufficiently established, LNT modelling is used as a default assumption;

Group C: Genotoxic carcinogens - for which a practical threshold is supported; and

Group D: Non-genotoxic carcinogens and non-DNA reactive carcinogens - a true threshold may be established associated with a NOAEL. 
SCOEL seeks to derive health-based OELs for carcinogens in Groups C and D and, if possible, apply risk-based assessments to Category A and B substances (Bolt \& Huici-Montagud, 2008; Bolt et al, 2004; EC, 2013).

\subsubsection{Additional notations}

In addition to recommending an $8 \mathrm{hr}$ TWA and $15 \mathrm{~min}$. STELs, OEL-setting committees also use additional notations, where appropriate, to assist in risk management decisions; these include, skin notation, respiratory sensitisation and noise. In the case of the latter notation, there is evidence that demonstrates a link between certain organic solvents and excessive noise in the workplace, leading to hearing loss in workers (Unlu et al., 2014).

\section{Occupational exposure to manganese}

The world-wide mine production of manganese ore was estimated by the US Geological Survey to be around 18 million metric tonnes in 2014 . Of that, $61 \%$ was produced in the Gabon, $16 \%$ in Australia, $14 \%$ in South Africa, $4 \%$ in Ghana, and $5 \%$ in a number of other countries $\left(U_{S G S}^{5}\right)$.

The main uses of manganese continue to be for the production of alloys (ferrous and nonferrous), particularly in the steel making industry, and it is estimated that around $89 \%$ to $94 \%$

${ }^{5}$ US Geological Survey (USGS); http://minerals.usgs.gov/minerals/pubs/mcs/2015/mcs2015.pdf 
of manganese ore is used as feedstock for manganese alloys (CPM, 2011). The remaining manganese ore is used in foundry and welding, accounting for less than $10 \%$ of manganese ore (CPM, 2011). It is estimated that $6 \%$ to $11 \%$ of manganese ore is used in the production of electrolytic manganese metal (EMM), electrolytic manganese dioxide (EMD), lithium manganese oxide, manganese sulphate, and other chemicals. As noted above, the key metallurgical uses of manganese are in steel, aluminium and copper, while the key nonmetallurgical uses of manganese are in batteries and agricultural feed and fungicides.

A review of workplace exposure to manganese was carried out by the Institute of Environment and Health (IEH) in 2004, and reported within a Criteria Document ${ }^{6}$ produced for the International Manganese Institute (IMnI). The review found that there was substantial variability in exposure levels to manganese both between and within individual industry sectors. The three sectors for which most data were available were mining, manganese metal and alloy production and battery manufacture. The highest and most variable exposures were in mining with a maximum concentration (arithmetic mean) of $114 \mathrm{mg} / \mathrm{m}^{3}$ as manganese in total dust reported for miners in an Iranian study (Boojar and Goodarzi, 2002). In comparison, the highest exposure concentration reported in a study of South African miners in a modern mine was $1.5 \mathrm{mg} / \mathrm{m}^{3}$ (Myers et al., 2002). These two studies, although contemporaneous, 179 show very large differences in exposure levels. This must be largely due to differences between modern high technology mining operations using efficient control measures, such as use of water sprays, good ventilation, and isolation of workers from sources of dust, and

\footnotetext{
${ }^{6}$ Available at: http://www.iehconsulting.co.uk/IEH_Consulting/IEHCPubs/HumExpRiskAssess/w17.pdf
} 
what must be assumed to be older, less controlled methods of extraction. Some high exposures were also reported for manganese metal and manganese alloy production with a maximum exposure concentration of $27 \mathrm{mg} / \mathrm{m}^{3}$ (inhalable) reported in a Norwegian smelter (Johnsen et al. 2010) though typical levels were much lower (geometric mean $=0.254 \mathrm{mg} / \mathrm{m}^{3}$ ). Exposure concentrations associated with battery manufacture ranged up to $11 \mathrm{mg} / \mathrm{m}^{3}$ as inhalable manganese in a Belgian study (Roels et al., 1992).

Importantly, the IEH review (IEH, 2004) specifically examined information about the concentrations of manganese in different size fractions, to derive conversion factors that could be used to assist in the interpretation of epidemiological studies in which different fractions of manganese in air had been measured (respirable, inhalable or total dust). The authors concluded that only a small proportion of inhalable manganese was of respirable size, although this varied by process (with exception of welding). A conversion factor of 1.2-3.2 was proposed to convert 'total' to 'inhalable' concentrations and a factor of 0.1-0.5 to convert 'total' concentrations to equivalent 'respirable 'concentrations (to allow cross study comparison).

The IEH review (IEH, 2004) also assessed the limited biological monitoring data that was available at the time of publication. The data showed considerable interindividual variability in blood manganese levels, although manganese exposed workers generally had higher blood manganese than unexposed. The data did not however, establish a clear relationship between exposure concentrations of manganese in air and blood manganese, and there was little 
evidence to support the use of blood manganese as a reliable exposure index. Over the range of studies reviewed, urinary manganese levels also varied substantially, even among the controls, however, almost all of the studies reported significant differences between controls and exposed workers. No clear relationship between airborne exposure and urinary levels on an individual basis was demonstrated.

\subsection{OEL setting for manganese}

In their review of the literature regarding occupational exposure to manganese in 2004 , the IEH proposed OELs of 0.1 and $0.5 \mathrm{mg} \mathrm{Mn} / \mathrm{m}^{3}$ for respirable and inhalable fractions respectively. Consideration of the levels and duration of exposure in the studies by Gibbs et al. (1999) and Myers et al. (2002), which found no neurological effects in exposed workers, and the study by Roels et al. (1992), which showed adverse neurological effects, was used as a basis for determining a NOEL and the proposed OELs; these were considered protective based on knowledge at the time.

However, an updated search of studies and reviews around the exposure and uptake of manganese and of neurotoxic effects in workers, published subsequent to the IEH 2004 review (as detailed in Appendix A), suggest that some non-clinical neurofunctional adverse effects may be occurring around the OELs proposed by the IEH 2004 review. 
For OEL setting, as in all risk assessments, often the weakest component of key occupational studies for manganese has been the exposure assessment, which is as important a consideration as the toxicological health outcome. For manganese, cross study comparisons of data also remain limited by the variable approach taken to sampling by the authors.

A number of investigators have reported exposure measurements for the respirable, total/inhalable or other size fractions of manganese which are expected to have different bioavailabilities (ATSDR, 2012). The particle size of inhaled manganese would be anticipated to affect uptake and distribution and it is conventionally assumed that a much higher absorption of inhaled material in the respirable fraction is deposited in the lungs than of coarser material, which is largely swallowed. Several studies provide information about particle size in individual workplace environments (Ellingsen et al., 2003; Harris et al., 2005; Pearson and Greenway, 2005; Berlinger et al., 2007; Michalke et al., 2007; Berlinger et al., 2008; Ellingsen et al., 2008; Ross et al., 2009; Keane et al., 2010; Lehnert et al., 2012). As would be anticipated, there are substantial differences in the size distribution of airborne manganese in different workplace environments with processes that generate fume giving rise to aerosols with a much higher respirable content (as a percentage of total/inhalable manganese) than activities such as breaking up ore or cutting manganese containing materials. However, the ratio of respirable to inhalable $\mathrm{Mn}$ in workplace air is generally in the range 0.1-0.5. 
246 A further issue for manganese regarding exposure monitoring methodology is the unexplained variability observed in mean blood manganese levels reported for non-exposed controls in workplace studies, as well as in studies of the general population. Currently, therefore, it is not clear whether real differences in mean blood manganese levels exist between different population groups; potential causes for such differences could include factors such as dietary intake of manganese and iron. Alternatively, the differences may arise from differences in measurement protocols, including the sampling regimes adopted by the authors as it was notable in the identified literature that the validated NIOSH methods for metals in urine and blood were not widely used.

Significant exposure via the skin is unlikely in most workplaces where manganese is present as the nature of the tasks being undertaken means that workers are likely to be wearing gloves and protective clothing and there is limited potential for direct skin contact to occur. Inadvertent ingestion is most likely to arise in individuals with poor personal hygiene, particularly where there are no strict procedures to ensure that workwear is removed and exposed skin washed prior to breaks in the working day and at the end of the work shift (IEH, 2004).

\subsubsection{Assessment of available neurotoxicity data}

In their review, the IEH (IEH, 2004) noted that the available evidence at the time of publication indicated that subtle subclinical neurological effects in humans were the most critical endpoint associated with chronic low-level occupational exposure to manganese. This is 
suggested to be linked to the accumulation of manganese in brain tissue following inhalation, with the basal ganglia region being a primary target of toxicity. These changes were, and still are, considered a suitable basis for setting an OEL. Indeed there is a reasonable body of evidence from human cohort studies that occupational manganese exposure may induce subtle neurotoxic changes and that current occupational levels of manganese may be associated with the onset of some symptoms of manganism (EC, 2011; ATSDR, 2012).

Whilst there is a growing body of evidence that occupational exposure to manganese at levels below those associating with the onset of manganism may elicit subtle neurofunctional perturbations (Meyer-Baron et al., 2009 and 2013), such changes are only detectable using specialised testing and represent sub-clinical effects. Studies that support the existence of such an association are subject, to varying extent, to methodological limitations. However, recent work has strengthened the evidence base that there is a lack of progression (or, in some cases, regression) of the subtle changes once the occupational exposure is reduced or stopped (Bouchard et al. 2007b and 2007c; Wastensson et al, 2012). Furthermore, there is potential (Bowler et al., 2011).

Many of the studies that have been reported since the IEH review (IEH, 2004) have sought to use those neurofunctional tests that appear to be particularly sensitive at identifying the subtle neurological changes thought to associate with manganese toxicity. These recent 
studies have, however, continued to be limited to a significant extent by continued reliance on cross-sectional designs and also by use of potentially unreliable exposure estimation methods. Consequently the strength of the potential association between manganese exposure and these subtle subclinical cognitive or neuromotor changes is still poorly characterised and the relevance of these minor differences in terms of either their clinical or quality of life consequences remains unknown (SCOEL, 2011; ACGIH, 2013).

\subsection{Current and proposed OELs for manganese}

Since the OELs were proposed in the review by the IEH (IEH, 2004) there has been much activity around the setting of OELs for manganese by a number of the key OEL setting bodies. In addition, the EU SCOEL has published recommendations for OELS for manganese and its inorganic compounds ${ }^{7}$. Table 1 shows current OELs from the OEL setting bodies, with the OELS proposed by the IEH in 2004 included for comparison. It should be noted that the recent evaluations of the SCOEL, MAK and the ACGIH suggest that it may be possible to establish reliable health-based OELs for neurofunctional changes which can be considered true NOAELS for these effects.

\footnotetext{
${ }^{7}$ It should be noted that at the time of writing, this recommendation has not yet passed though the EU DG Employment, Social Affairs and Inclusion's appropriate committee procedures and thus, it is not known whether the document and its recommended OELs will be accepted or modified.
} 
Table 1. Current and proposed OELs for manganese

\begin{tabular}{|c|c|c|}
\hline & $\begin{array}{c}\text { Respirable OEL } \\
\left(\mathrm{mg} \mathrm{Mn} / \mathrm{m}^{3}\right)\end{array}$ & $\begin{array}{l}\text { Inhalable OEL } \\
\left(\mathrm{mg} \mathrm{Mn} / \mathrm{m}^{3}\right)\end{array}$ \\
\hline IEH (2004) & 0.1 & 0.5 \\
\hline \multicolumn{3}{|l|}{ OEL Setting Committees } \\
\hline SCOEL IOELV (2009 - 2011) & 0.05 & 0.2 \\
\hline MAK Commission (2010) & 0.02 & 0.2 \\
\hline ACGIH TLV-TWA (2011 - 2013) & 0.02 & 0.1 \\
\hline
\end{tabular}

IEH - The Institute of Environment and Health; SCOEL - The Scientific Committee on Occupational Exposure

Limits; IOELV - indicative occupational exposure limit value; MAK - Permanent Senate Commission for the

Conference of Governmental Industrial Hygienists ; TLV-TWA - Threshold Limit Value-Time-Weighted Average.

The derivation of each of these OELs is discussed below, with details of individual studies given in Table 2.

\subsubsection{The Scientific Committee on Occupational Exposure Limits}

The Scientific Committee on Occupational Exposure Limits (SCOEL) recommendations note that there is a substantial literature on the effects of manganese on the human nervous system and that high exposures can result in severe neurotoxic signs and symptoms, some of which resemble those of idiopathic Parkinson's disease. It concludes the clinical symptoms 
associated with manganism, such as movement disorders and neurological dysfunction, have generally been reported at exposure levels above $5 \mathrm{mg} / \mathrm{m}^{3}$. However, it noted that more recently, several studies on lower occupational exposures to manganese have reported less severe, subtle, non-clinical neurofunctional effects. These subtle effects usually consist of deterioration in motor function and co-ordination and, as such, may constitute manganeseinduced changes in the same area of the brain as manganism, that is the basal ganglia and, in particular, the globus pallidus.

In their findings, SCOEL state that it was not possible to identify one study on which to base the IOELVs as the data is highly heterogeneous (e.g. different types of industry, different manganese compounds and particle sizes, different study designs and different neurofunctional measurements). They recommended a global approach using the most methodologically-sound studies (i.e. showed adverse neurological effects and identified a point-of-departure (POD) in the dose-effect/response relationship), as used by IEH (2004). The SCOEL Recommendation, based on studies by (Roels et al., 1992; Gibbs et al., 1999; Myers et al., 2003; Young et al., 2005; Bast-Pettersen et al., 2004; Ellingsen et al., 2008; Lucchini et al. 1999 in HC, 2008) was thus as follows:

"A reasonable respirable IOELV of $0.05 \mathrm{mg} / \mathrm{m}^{3}$ can be recommended, and a reasonable inhalable IOELV of $0.2 \mathrm{mg} / \mathrm{m}^{3}$ is also recommended. While recommending these values, SCOEL recognises that the overall systemic absorption of coarser particles (>respirable) is probably substantially lower than for the respirable fraction. Thus, SCOEL recommends both a respirable and an inhalable IOELV which would need to be observed conjointly". 
SCOEL are thus drawing attention to the fact that these recommended values were highly precautionary and would protect against any neurofunctional change. Indeed, SCOEL noted that the changes reported are subtle early neurofunctional effects which are non-clinical in nature and are only detected at a statistical level between groups of workers. In addition, some of the subtle neurofunctional effects of manganese on the CNS are reversible although the degree of reversibility has not been defined.

In addition to these airborne IOELVs, SCOEL agreed with the views on biological monitoring in the 2004 CD (IEH, 2004) on which the SCOEL/SUM is mainly based. That it was not possible to recommend a health based biological monitoring standard due to the poor correlation between airborne manganese and either blood or urine concentrations of manganese. However, they noted that in Germany, a Biologischer Arbeitsstoff-Referenzwert (BAR) value of $15 \mu \mathrm{g} / \mathrm{l}$ blood has been established by the MAK Commission. This value represents exposed to manganese, but of working age (EC, 2011).

3.2.2 The Permanent Senate Commission for the Investigation of Health Hazards of Chemical Compounds in the Work Area Compounds in the Work Area (MAK Commission) in Germany revised their MAK values for manganese and its inorganic compounds in 2010. They followed the recommendations of the IEH (IEH, 2004) with regards to setting values for both respirable and inhalable fractions. 
Although a comprehensive evaluation, they noted that "as toxic effects on the airways and lungs (so-called manganese pneumonia) after repeated exposure to manganese are not induced below concentrations of at least $1 \mathrm{mg} / \mathrm{m}^{3}$ (IEH 2004), its neurotoxic effects will be used for derivation of the MAK value". They thus concentrated almost entirely on human neurofunctional investigations and classified these studies into those to be considered for OEL setting, for inhalable and respirable fractions separately, which met the following criteria (Category A studies): exposure to manganese at the workplace by inhalation, application of standardised neuropsychological test procedures, parallel investigation of a non-exposed control group, valid data on manganese concentrations in the ambient air, as well as the control of major confounders. Studies that did not meet all criteria were assigned as Category B, with studies of welders assigned to Category $C$. The derivation of the MAK value was established on the basis of studies in Category A, with those in Categories B and C used as supporting evidence (Chia et al., 1993; Lucchini et al., 1999; Mergler et al., 1994; Gibbs et al., 1999; Young et al., 2005; Myers et al., 2003; Bast-Pettersen et al., 2004; Meyer-Baron et al., 2009).

As with other recently-active OEL-setting committees, the MAK considered that the most sensitive endpoint for deriving workplace threshold concentrations for manganese was the occurrence of preclinical neurotoxic effects after inhalation. They examined in detail exposure with measurements in motor and cognitive function and looked for concordance between studies. For the derivation of a MAK value based on neurofunctional toxicity data, the MAK stressed that it needs to be shown that (a) no single effect is involved in only one study, (b) different studies provide evidence of a similar effect at comparable dose ranges, (c) the 
observed performance impairments are compatible with the proposed neurotoxic mechanisms and (d) the impairments in performance observed can be seen as indicators of clinical changes in exposures either extremely high or lasting for many years. If these prerequisites are met in the case of manganese, the impairments in performance are to be classified as adverse effects, as they constitute early signs of clinically-relevant changes.

They also stress that in deriving a MAK value from epidemiological cross-sectional studies, unlike animal investigations, no direct derivation of a NOAEC or LOAEC is possible, as only an average value is available for manganese exposure in the exposed group.

\subsubsection{The American Conference of Governmental Industrial Hygienists}

The American Conference of Governmental Industrial Hygienists (US ACGIH) have had a number of Draft notices of intended changes (NIC) for manganese, elemental and inorganic compounds, published over the last few years, with a final accepted version being published in 2013 (ACGIH, 2013). It is important to note that ACGIH also propose both respirable and inhalable values.

In the development of their recommendations, the ACGIH first cite the study by Roels et al. (1992) which proposed that a respirable OEL of $0.036 \mathrm{mg} \mathrm{Mn} / \mathrm{m}^{3}$ would protect most workers from neurological effects. Further analysis of this study data by the ATSDR (ATSDR, 2012) using a benchmark dose approach, allowed the ACGIH to calculate a $\mathrm{BMDL}_{10}$ of $0.07 \mathrm{mg}$ $\mathrm{Mn} / \mathrm{m}^{3}$ as a NOAEL. 
414 In their recommendation, the ACGIH also noted the analysis by Crump and Rousseau (1999) 415 of the follow-up study by Roels (1987) which showed that after 11 years further exposure to 416 Mn, there was some evidence that the previously reported sub-clinical neurological effects 417 were not progressing. Next, they cited the study by Mergler et al. (1994) in which workers were exposed to a median level of $0.032 \mathrm{mg} \mathrm{Mn} / \mathrm{m}^{3}$ (respirable). The workers in this study were examined 14 years following cessation of exposure and it was noted that some of the previously reported neurobehavioural changes were still persisting (Bouchard et al. 2007a and b). The study by Lucchini et al. (1999) showed an LOAEL for neurological effects of about $0.1 \mathrm{Mn} / \mathrm{m}^{3}$ (total dust) after an average of 11.5 years. This corresponded to a respirable geometric mean concentration of $0.036 \mathrm{mg} \mathrm{Mn} / \mathrm{m}^{3}$.

The ACGIH noted that the Bast-Pettersen et al. (2004) study reported tremor (impaired hand steadiness) at a geometric mean level of $0.036 \mathrm{mg} / \mathrm{Mn} / \mathrm{m}^{3}$ (respirable), whilst in a study on South African manganese smelters, Young et al. (2005) showed increased neurobehavioural changes in workers exposed to 0.01-0.04 $\mathrm{mg} \mathrm{Mn} / \mathrm{m}^{3}$ (respirable).

In developing the rationale for their TLV, the ACGIH noted that the LOAELs for neurological effects derived from the studies of Bast-Pettersen et al. (2004), Lucchini et al. (1999), Mergler et al. (1994) and Roels et al. (1992) which are respectively, 0.036, 0.032, 0.038 and $0.036 \mathrm{mg}$ $\mathrm{Mn} / \mathrm{m}^{3}$ (respirable) are in close agreement. Thus, a TLV-TWA of $0.02 \mathrm{mg} \mathbf{M n} / \mathrm{m}^{3}$ respirable 
reduce the potential for preclinical, neurophysiological and neuropsychological effects in manganese-exposed workers." It was noted by the ACGIH that this value is 1.5-2.0 times lower than the range of LOAELs observed.

However, the ACGIH also stated that in some occupational situations, exposure to manganese was to aerosols with a substantial fraction greater than $4 \mu \mathrm{m}$ MMAD (respirable range) and thus a supplementary TLV-TWA of $0.1 \mathrm{mg} \mathrm{Mn} / \mathrm{m}^{3}$ inhalable particulate matter was recommended for conditions where particles $>4 \mu \mathrm{m}$ are anticipated. They note that the ratio of inhalable to respirable mass may vary from 1:1 to 10:1 but, have used a midpoint ratio for conversion of 5;1, and cited the previous IEH Criteria Document (IEH 2004 ), which also gave this ratio, in support of their approach. They finally note that if the inhalable TLV-TWA is used, then this should be in addition to the respirable TLV-TWA.

\subsection{Assessment of key studies used for derivation of OELS}

As discussed previously, often the weakest component of key studies has been the exposure assessment, which is as important as the toxicological health outcome. In the case of occupational exposure to manganese and its inorganic compounds, usually the neurofunctional tests although very variable and many without defined normative data, have been reasonably well described and with the use of appropriate control groups. However, in many cases the studies have contained unreliable estimates of long-term exposure often based upon limited exposure data. 
457 An outline of the studies that have been included in the derivation of OELs by the IEH (IEH, 458 2004) and the OEL setting bodies, SCOEL, MAK and ACGIH is given in Table 2. In assessing 459 these studies, one of the key considerations must be the reliability of the exposure 460 assessments undertaken and what influence that may have on the overall OEL. 
Table 2 Critique of exposure assessment in studies consideredby OEL setting committees to derive OELs for manganese and its inorganic compounds

\begin{tabular}{|c|c|c|}
\hline Study Author & Included in OEL derivation & Comments on Exposure Assessment \\
\hline Lauwreys et al., 1985 & IEH 2004 & $\begin{array}{l}\text { Only current (not historical) exposure data available. Exposures ranged from 1-19 years } \\
\text { (mean } 7.9 \text { ), } 8 \text { hour TWA ranged from } 0.07-8.61 \mathrm{mg} / \mathrm{m}^{3} \text { (arithmetic and geometric mean } \\
\text { values } 1.33 \text { and } 0.94 \mathrm{mg} / \mathrm{m}^{3} \text { respectively) }-80 \text { samples - authors indicated that past } \\
\text { exposures may have been lower as production rates were lower (however industrial } \\
\text { hygiene has generally improved through time), fertility effects only examined for exposed } \\
\text { group as a whole, not in relation to relative current exposure levels or any sort of } \\
\text { cumulative exposure index (CEI). } \\
\text { Critique: study considered not helpful to establishing an OEL. }\end{array}$ \\
\hline Roels et al., 1992 & IEH 2004; EC 2011; ACGIH 2013 & $\begin{array}{l}\text { Personal measurements of respirable and inhalable exposures to Mn. Inhalable } \\
\text { measurements based on grit pots in cyclone samplers which is not an approved sampling } \\
\text { method. Cumulative exposure estimated on basis of current exposure levels and job history } \\
\text { - some potential to under-estimate cumulative exposure, if exposures were less well } \\
\text { controlled in the past however, specific statement to effect that work processes have not } \\
\text { been modified over previous } 15 \text { years is included and measurements would therefore be } \\
\text { expected to be representative of past exposure. } \\
\text { Exposure response relationship illustrated for lifetime cumulative exposure as a continuous } \\
\text { variable in a non-threshold model, and also for exposure categorised as }<600,100-1200 \text {, } \\
>1200 \text { ug } \mathrm{Mn} / \mathrm{m}^{3} \text {.years with apparent effects in }<600 \text { group - nothing to pinpoint a } \\
\text { threshold. The upper bound estimated ED05 level of the investigated endpoints were } 3575 \\
\text { ug Mn/m } 3 \text {.year total and } 730 \text { ug Mn } \mathrm{mg} / \mathrm{m}^{3} \text {.year respirable - these levels are subsequently } \\
\text { described as threshold for effects. } \\
\text { Critique: study did not use an approved sampling method which may impact on exposure } \\
\text { estimates. }\end{array}$ \\
\hline Mergler et al., 1994 & ACGIH 2013 & $\begin{array}{l}\text { Static samples at } 13 \text { representative locations through facility, sampling and analytical } \\
\text { procedures described, no QC details - may not be closely related to actual personal } \\
\text { exposure; total and respirable Mn measured. Only } 38 \text { samples were collected - not many } \\
\text { to characterise exposure across workplace and no evidence that investigators tried to } \\
\text { establish levels of exposure associated with different job functions. It is stated that dust } \\
\text { levels had previously been much higher. }\end{array}$ \\
\hline
\end{tabular}




\begin{tabular}{|c|c|c|}
\hline & & $\begin{array}{l}\text { Critique: the relationship between MnAir and neurobehavioural effects does not appear } \\
\text { to have been investigated and the study is not helpful to the setting of an OEL }\end{array}$ \\
\hline Gibbs et al., 1999 & IEH 2004; EC 2011 & $\begin{array}{l}\text { Current (1997) respirable and total concs of Mn were measured for } 12 \text { job categories (not } \\
\text { given) and arithmetic mean used to estimate pre-1997 exposure levels for each job } \\
\text { category, taking account of process and work practice changes and the results of } 15 \text { minute } \\
\text { compliance samples collected before and after such changes. Job histories derived from } \\
\text { personnel records, interview and pay roll records and used to calculate cumulative } \\
\text { exposures. The sampling and analysis procedures are described but no QC information } \\
\text { provided. The number of samples collected does not appear to be stated and there is no } \\
\text { information about the variability of the exposure estimates for each job category. There is a } \\
\text { small uncertainty around the back projection of exposure concentrations from } 1997 \\
\text { measurements - possibility that past exposures could be under-estimated. Results of } \\
\text { neurobehavioural tests assessed against previous } 30 \text { days, years and lifetime exposure - } \\
\text { treated as continuous variable - no artefacts associated with grouping of exposures. } \\
\text { Critique: It is not certain how much confidence to ascribe to the exposure estimates. }\end{array}$ \\
\hline Lucchini et al., 1999 & $\begin{array}{l}\text { IEH 2004; EC 2011; Health Canada 2012; } \\
\text { MAK 2010; ACGIH } 2013 .\end{array}$ & $\begin{array}{l}\text { Air sampling performed } 1 \text { month before neurobehavioural testing, respirable and total Mn } \\
\text { concentrations determined using personal and stationary sampling - methods are } \\
\text { described, no QC details, Cumulative exposure index (CEI) calculated by multiplying average } \\
\text { annual airborne Mn concentration characteristic of each job performed by the subject } \\
\text { during his work history and years exposed with adjustment for inhalation rate for different } \\
\text { task workloads. No adjustment made for any changes in work practice - possible that } \\
\text { measured exposures would be less than historic exposure concentrations. MnB and MnU } \\
\text { determined for samples collected at time of nuerobehavioural test. Plot of CEI and MnB } \\
\text { indicates an apparent relationship - no information is provided as to the relationship } \\
\text { between CEI and current exposure levels or MnB and current exposure levels. } \\
\text { Critique: the neurobehavioural test results are not analysed in relation to MnAir or CEI, so } \\
\text { the paper is not informative about the exposure levels that give rise to effects versus } \\
\text { those that don't - some effects seen in a group with current exposures that range from } \\
\mathbf{0 . 0 2 6 - 0 . 7 5 ~} \text { mgm-3 as total Mn. Unlikely to be helpful in setting an OEL. }\end{array}$ \\
\hline Crump \& Rosseau , 1999 & IEH 2004 & $\begin{array}{l}\text { No } \mathrm{Mn} \text { Air data and results not assessed in terms of cumulative exposure to } \mathrm{Mn} \text { - could be } \\
\text { assumed that air Mn concentrations similar to those described by Roels et al., in earlier } \\
\text { study at same plant. } \\
\text { Critique: overall not helpful to setting an OEL - confirms previously described levels of } \\
\text { exposure at plant have adverse effects but not enough to derive a NOAEL or LOAEL. }\end{array}$ \\
\hline
\end{tabular}




\begin{tabular}{|c|c|c|}
\hline Myers et al., 2002 & IEH 2004 & $\begin{array}{l}\text { Base-line cross-sectional study in miners working in deep mining and opencast. Largest } \\
\text { study, modern technology. Well conducted and described. Inhalable fraction }=1.4 \text { times } \\
\text { total dust. No correlation between } \mathrm{MnA} \text { andMnB. } \\
\text { Critique: good quality exposure data recorded. }\end{array}$ \\
\hline Clewell et al., 2003 & ACGIH 2012 & $\begin{array}{l}\text { Calculation of BMD for datasets underlying Roels et al., (1992) and Gibbs et al., (1999) } \\
\text { studies. Some approximations required to derive exposure concentrations for individual } \\
\text { workers. Analysis based on current exposure concentrations (based around arithmetic } \\
\text { mean), given the likely interindividual variability in exposure in each exposure group, there } \\
\text { could be significant under or overestimates of exposure at an individual level) - CEI was not } \\
\text { investigated (which seems a major weakness). } \\
\text { Critique: the elegance of presentation hides considerable uncertainty in the most } \\
\text { appropriate way to handle the exposure data. }\end{array}$ \\
\hline Myers et al., 2003a & EC 2011; & $\begin{array}{l}\text { Exposure assessment based on measurements made to meet regulatory requirements with } \\
\text { some additional measurements made to confirm reliability of routine measurements. } \\
\text { NIOSH methods of analysis - no detail on QC but no reason to anticipate that data would } \\
\text { not be reliable. Measurements made for individuals representative of task being assessed - } \\
\text { data collected over } 4 \text { years - should have a reasonable long term average TWA for each } \\
\text { occupational group. Individual mean and cumulative exposure assessments made by } \\
\text { multiplying concentration for each job times years worked in that job and average } \\
\text { exposure intensity and average exposure intensity calculated from cumulative exposure } \\
\text { divided by service life. Exposure treated as a continuous variable in analysis of exposure- } \\
\text { response relations. } \\
\text { Critique: unsure how representative measurements are of historical exposure which may } \\
\text { have been higher. }\end{array}$ \\
\hline Myers et al., 2003b & MAK 2010; & $\begin{array}{l}\text { Analytical methods and QC well described, but time period over which sampling conducted } \\
\text { not given. } \\
\text { Critique: implication that exposure assessment based on a snapshot of exposure } \\
\text { concentrations rather than being representative of long term mean exposure levels. }\end{array}$ \\
\hline Bast-Pettersen et al., 2004 & ACGIH 2013; EC 2011 & $\begin{array}{l}\text { Mn Air - personal full shift sampling for } 3 \text { days for each individual on days close to their } \\
\text { neuopsychological examination. No information about long term variation in individual } \\
\text { exposure levels. Urine and Blood samples taken. Exposure data treated as continuous } \\
\text { variable. Plots of data as groups with differing duration of exposure. Data examined against } \\
\text { low, medium and high MnB. Critique: exposure data may be unrepresentative of past } \\
\text { exposures - potential for effects of exposure to low concentrations to be over-estimated. }\end{array}$ \\
\hline
\end{tabular}




\begin{tabular}{|c|c|c|}
\hline Young et al., 2005 & BD 2013; EC 2011; ACGIH 2013 & $\begin{array}{l}\text { Related to Myers (2003b) smelter study - not sure whether same source of exposure data. } \\
310 \text { inhalable dust concentrations, } 98 \text { personal dust concentrations - suspect single } \\
\text { measurement campaign - not clear whether representative of historical exposure levels - } \\
\text { cumulative exposure indices developed but then divided by duration of exposure to give } \\
\text { average intensity. Study focussed on respirable Mn - estimation of respirable Mn where } \\
\text { gaps in job exposure measurement. Link given to more detailed description of how } \\
\text { exposure estimates were derived is broken. } \\
\text { Critique: response examined by exposure category by average intensity of exposure } \\
\text { rather than cumulative exposure - so issue of whether central tendency, upper or lower } \\
\text { bound concentration most relevant plus issues of whether cumulative exposure and/or } \\
\text { peak exposures more relevant. Authors state that only the intensity groupings presented } \\
\text { as cumulative exposures gave similar results - which seems surprising. }\end{array}$ \\
\hline Ellingsen et al., 2008 & EC 2011 & $\begin{array}{l}\text { Details of sampling and analysis in Ellingsen et al (2006). Sampling conducted as a single } \\
\text { survey- blood and urine samples for } 96 \text { welders - } 180 \text { air samples collected on preceeding } 2 \\
\text { days for each welder providing biological samples, QC for analysis described, evidence of a } \\
\text { methodological approach to the sampling. } \\
\text { Critique: no information about day to day variability of the exposure of any individual - } \\
\text { measurements reflect average for group; analysis examined MnB, MnAir and duration of } \\
\text { exposure but not cumulative exposure. Exposure data may be unrepresentative of past } \\
\text { exposures - potential for effects of exposure to low concentrations to be over-estimated. } \\
\text { No information that would confirm MnB, MnAir for individuals that were used in the } \\
\text { analysis were actually representative of long term exposure for those individuals. The } \\
\text { study tells you about the average level of neurobehavioural impairment versus an } \\
\text { average cumulative exposure as MnAir but is not going to provide reliable dose-response } \\
\text { information beyond that - the determination of MnAir, however, is likely to be reliable. }\end{array}$ \\
\hline $\begin{array}{l}\text { Meyer-Baron et al., } 2009 \\
\text { (meta-analysis) } 13 \text { studies } \\
\text { included: }\end{array}$ & MAK 2010 & \\
\hline Bast-Pettersen et al., 2004 & & See above \\
\hline $\begin{array}{l}\text { Blond \&Netterstrom, 2007; } \\
\text { Blond et al., } 2007\end{array}$ & & $\begin{array}{l}\text { No details given of how } \mathrm{Mn} \text { measurements made. Dust measurements made in } 1970 \mathrm{~s} \\
\text { varied from } 0.7-62.2 \mathrm{mg} / \mathrm{m}^{3} \text { as total dust, } \mathrm{Mn} 1-3 \%, \mathrm{Mn} \text { in air assumed to have been } \\
\text { between } 0.01 \text { and } 1.9 \mathrm{mg} / \mathrm{m}^{3} \text {, median } 1.1 \mathrm{mg} / \mathrm{m}^{3} \text {. Personal and static measurements of } \mathrm{Mn} \\
\text { made in } 1990 \mathrm{~s} \text { - personal inside airfed helmets, static outside, much higher, stated that }\end{array}$ \\
\hline
\end{tabular}


compliance with use of air fed helmets was $<100 \%$ - total $\mathrm{Mn} 0.01-0.84 \mathrm{mg} / \mathrm{m}^{3}$, median 0.03. Median $\mathrm{PbB}$ in 1989 was $0.79 \mathrm{umol} / \mathrm{I}=<2 \mathrm{ug} / \mathrm{dL}$.

Critique: comparison made between exposed and unexposed groups - no exposure response information in terms of threshold of effects, contribution of higher levels of historical exposure or consideration of cumulative exposure.

Regular annual monitoring of exposure had been undertaken for many years - personal samples for a representative selection of workers. Neurobehavioural effects not considered in relation to airMn or $\mathrm{CEI}$ - air monitoring results show steep decline in air $\mathrm{Mn}$ through time - so workers received historical exposures that were vastly greater than those experienced at the time of the study.

Critique: study not informative about relationship between air $\mathrm{Mn}$ and neurobehavioural effects.

Exposures quoted as total dust. No differentiation by job function or location reported. Critique: Well-conducted study but small sample size and lacking detail.

Cumulative exposure unable to be accurately estimated. Exposure categories derived from supervisors estimations of past exposure. There was a significant rank correlation between this subjective estimation of cumulative exposure and blood manganese levels but not urinary levels. On an individual basis, neither blood nor urinary manganese correlated with current exposure or with duration of exposure.

Critique: Well-conducted study with some indication of adverse effect of $\mathrm{Mn}$ exposure on respiratory system; however, respiratory findings not backed up in Roels et al., 1992.

Exposure assessment based on exposure times provided by Welders and the reported time spent on TIG or MIG welding - the welders appear to have been questioned some years after exposure - only 13 welders had been exposed to $\mathrm{Mn}$ and had welded for more than 
100 hours in high alloy Mn steel - small information base. Exposure to particles in breathing zone of welders measured in mid 1970 s was $10 \mathrm{mg} / \mathrm{m}^{3}$ for MIG and $1 \mathrm{mg} / \mathrm{m}^{3}$ for TIG - fumes from electrodes used contain 2-8\% Mn. Study focussed on biological monitoring - no relationship between $\mathrm{MnB}$ and former $\mathrm{Mn}$ exposure. Exposure response relationship reported for $\mathrm{Al}$.

Critique: no detailed investigation of exposure response relationships reported and no clear information provided about the levels of Mn exposure that were associated with neurobehavioural impairment.

Details of exposure measurements not given - not clear whether personal measurements of whether respirable or total (welding so probably predominantly respirable anyway); routine surveillance data from 1995-2002 showed concs of Mn ranging from 0.1-0.5 mgm3.

Critique: effects not looked at in relation to air $\mathrm{Mn}$ - probably not helpful in setting an OEL.

20 air samples were collected during welding -10 minute samples collected at height of breathing zone - implies not true personal samples - particularly as welders would have been wearing helmets - from these samples cumulative $\mathrm{Mn}$ exposures were calculated based on exposure duration - given the small number of measurements on which these estimated cumulative exposures are based, there is considerable uncertainty in their reliability. It is not stated how 8 hour TWAs were assessed on the basis on ten minute measurements.

Critique: although the study establishes neurobehavioural effects in the exposed workers (with an estimated mean exposure level) it does not provide information as to the level of exposures associated with NOAELs and LOAELs - neurobehavioural endpoints are not analysed against air Mn or CEI. 
From the critique of available exposure assessments carried out for the studies utilised by SCOEL, MAK and ACGIH, it is possible to identify the key studies based on reliability of the exposure data (although it should be noted that some have other remaining limitations) as

et al. (2004) and Ellingsen et al. (2008).

An important limitation of the above studies is a lack of standardisation of some test subjective. The main finding(s) from the neurological testing carried out as part of the above studies is detailed in Table 3.

Table 3 Outcome of neurological testing in key studies.

\begin{tabular}{|c|c|c|c|}
\hline Study & $\begin{array}{l}\text { Occupational } \\
\text { Group }\end{array}$ & Neurological testing & End-point \\
\hline Roels et al., 1992 & Battery workers & 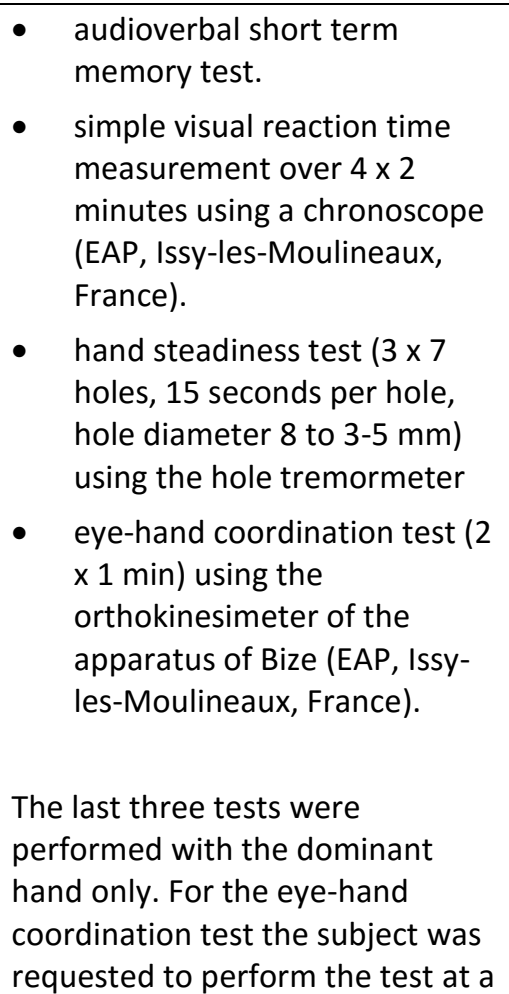 & $\begin{array}{l}\text { Decline in visual reaction } \\
\text { time,eye-hand } \\
\text { coordination, hand } \\
\text { steadiness. } \\
\text { LOAELs of: } \\
0.22 \mathrm{mg} / \mathrm{m} 3 \text { (resp) } \\
0.95 \mathrm{mg} / \mathrm{m} 3 \text { (total) } \\
\text { Based on increased risk } \\
\text { of hand tremor. } \\
\text { Logistic regression } \\
\text { LOAELs: } \\
\text { increased risk of } \\
\text { peripheral tremor (5\% } \\
\text { abnormal response } \\
\text { increment) when the } \\
\text { lifetime integrated } \\
\text { exposure to: } \\
\text { respirable manganese } \\
\text { dust exceeded } 3.575 \\
\text { (p=0.029) and to total }\end{array}$ \\
\hline
\end{tabular}


Table 3 Outcome of neurological testing in key studies.

\begin{tabular}{|c|c|c|c|}
\hline Study & $\begin{array}{l}\text { Occupational } \\
\text { Group }\end{array}$ & Neurological testing & End-point \\
\hline & & $\begin{array}{l}\text { speed imposed by a metronome (1 } \\
\text { hit/s). }\end{array}$ & $\begin{array}{l}\text { dust exceeded } 0.730 \\
\mathrm{mg} / \mathrm{m}^{3} \times \text { years }(p=0.054) .\end{array}$ \\
\hline Gibbs et al., 1999 & Smelters & $\begin{array}{l}\text { - } \quad \text { hand steadiness (movemap } \\
\text { steady; movemap square; } \\
\text { EAP tremometer) } \\
\text { - Hand-eye co-ordination (EAP } \\
\text { Orthokinisimeter) } \\
\text { - } \quad \text { Rapidity of motion (4 choice } \\
\text { reaction time; finger tapping) } \\
\text { mood and } \\
\text { neuropsychological healh } \\
\text { questionnaire. }\end{array}$ & $\begin{array}{l}\text { NOAELs of: } \\
0.04 \mathrm{mg} / \mathrm{m} 3 \text { (resp) } \\
0.11 \mathrm{mg} / \mathrm{m} 3 \text { (total) } \\
\text { Based on lack of } \\
\text { neurobehavioural } \\
\text { changes at this level of } \\
\text { exposure. }\end{array}$ \\
\hline $\begin{array}{l}\text { Myers et al., } \\
2003 a\end{array}$ & Miners & $\begin{array}{l}\text { - } \quad \text { Maximum forward digit span } \\
\text { - } \text { Maximum backwards digit } \\
\text { - } \quad \text { Digit symbol score } \\
\text { - } \quad \text { Mean reaction time. }\end{array}$ & $\begin{array}{l}\text { NOAEL of: } \\
0.2 \mathrm{mg} / \mathrm{m} 3 \text { (total) based } \\
\text { on lack of } \\
\text { neurobehavioural } \\
\text { changes at this level of } \\
\text { exposure. }\end{array}$ \\
\hline $\begin{array}{l}\text { Bast-Pettersen et } \\
\text { al., } 2004\end{array}$ & Smelters & $\begin{array}{l}\text { - } \quad \text { Neuropsychiatric } \\
\text { - } \quad \text { Wuestionnaire. } \\
\text { - } \text { scale. } \\
\text { - } \quad \text { Tigit Symbolers adult intelligence } \\
\text { - } \quad \text { Stroop test. } \\
\text { - } \quad \text { Digit Span. } \\
\text { - } \quad \text { Benton test. } \\
\text { - } \quad \text { Kløve-Matthews Motor } \\
\text { - } \quad \text { Tremor test. } \\
\text { - } \quad \text { Finger Tapping. } \\
\text { - } \quad \text { Foot Tapping. } \\
\text { - } \quad \text { Dynamometer. } \\
\text { - } \quad \text { Grooved Peg-board test. } \\
\text { - } \quad \text { CATSYS System. } \\
\text { - } \quad \text { Luria-Nebraska Thumb/Finger } \\
\text { - Sequential Touch. } \\
\text { - } \quad \text { Himple Reaction Time test. } \\
\text { - }\end{array}$ & $\begin{array}{l}\text { LOAELS of: } \\
0.036 \mathrm{mg} / \mathrm{m} 3 \text { (resp) } \\
0.301 \mathrm{mg} / \mathrm{m} 3 \text { (inhal) } \\
\text { Based on hand tremor. }\end{array}$ \\
\hline $\begin{array}{l}\text { Ellingsen et } \\
\text { al.,2008 }\end{array}$ & Welders & $\begin{array}{ll}\text { - } & \text { Questionnaire Q } 16 . \\
\text { - } & \text { Digit Symbol. } \\
\text { - } & \text { Digit Span. } \\
\text { - } & \text { Finger Tapping. } \\
\text { - } & \text { Foot Tapping. }\end{array}$ & $\begin{array}{l}\text { LOAELs of : } \\
0.338 \mathrm{mg} / \mathrm{m} 3 \text { (respirable) } \\
0.423 \mathrm{mg} / \mathrm{m} 3 \text { (total) } \\
\text { NOAELs of: } \\
0.110 \mathrm{mg} / \mathrm{m} 3 \text { (respirable) }\end{array}$ \\
\hline
\end{tabular}


Table 3 Outcome of neurological testing in key studies.

476

477

478

479

480

481

482

483

484

485

486

487

488

489

490

491

492

493

494

\begin{tabular}{|c|c|c|c|}
\hline Study & $\begin{array}{l}\text { Occupational } \\
\text { Group }\end{array}$ & Neurological testing & End-point \\
\hline & & $\begin{array}{l}\text { - } \text { Dynamometer. } \\
\text { - } \text { CATSYS Postural Sway test. } \\
\text { - } \quad \text { CATSYS Maximum Frequency } \\
\text { test. } \\
\text { - Kløve-Matthews Static } \\
\text { Steadiness test. }\end{array}$ & $\begin{array}{l}0.137 \mathrm{mg} / \mathrm{m} 3 \text { (total) } \\
\text { Based on impaired finger } \\
\text { Tapping speed }\end{array}$ \\
\hline
\end{tabular}

For some of the neurofunctional tests used in the above investigations there are clear NOAELs and for others there are LOAELs. In the case of LOAELs it is sometimes difficult to appreciate what the significance of the functional outcome may be, as all the findings are considered sub-clinical at worst. This is further complicated by the fact that for many of these neurofunctional tests (e.g. eye-hand coordination) there is little or no normative data in order to give any changes seen in some of these studies a 'real-life' context. Where such data does exist, such as for visual reaction time, the significant differences in mean RT between control and exposed groups noted in the study by Roels et al. (1992) are well below those seen with aging (Spreen et al., 2006). It is therefore difficult to judge whether the non-clinical effects for visual reaction time described by Roels et al. (1992) would impact on the quality of life of exposed workers.

\section{Conclusions}

The evidence base described above highlights the continued concerns that exist with regard to several potential adverse health effects that may occur following occupational exposure to manganese and its inorganic compounds. However, as previously discussed, the most critical effect for humans associated with chronic low-dose occupational exposures remains some 
subtle non-clinical neurological changes in neuromotor and cognitive functions (shown by endpoints of tests associated with motor speed and speed of information processing). These are considered to be the lead effects since they are detectable at the lowest occupational exposure scenarios available. Hence, any health-based OEL based on these endpoints will be fully protective against any other possible health effect. It should be noted however, that interpretation of such subtle changes may be subject to variability both between tests and within study groups, making precise judgement of associated exposure levels difficult.

Although all the reviewed studies relating to neurological changes in workers have concluded that the effects are subtle and non-clinical in nature, it is apparent that there has been a tendency across regulatory guideline-setting bodies to establish somewhat lower OELs than those proposed in the review by the IEH (IEH, 2004); this applies to both inhalable and respirable fractions. The recent OELs proposed by the ACGIH in 2013, the SCOEL in 2011 and the MAK in 2010 are health-based in nature and relate to establishing a level at which no effect, even if extremely subtle in nature, would be anticipated to occur over a working lifetime of 40 years; i.e., they are essentially derivations of a NOAEL.

Additional evidence from a few new longitudinal investigations has reinforced the suggestion that subtle neurological effects detected in some repeated studies may not progress once exposure has ceased or been reduced. However, it is now clear that not all changes are fully reversible once established. 
There is still some question as to the significance of the small non-clinical neurological changes seen in exposed workers regarding their consequences in terms of both human

519 health and well-being. That is, it remains unclear if they represent key early markers of an increased risk of developing more serious neurological disorders (including manganism) in

521 later life or if they are of little or no consequence to the individual worker.

Based upon the overall evidence base, it is concluded here that the 8-hr time weighted averages (TWA) for respirable and inhalable fractions as recommended by the SCOEL in 2011 are the most methodologically-sound, as they are based on the best available studies most suited to the development of health-based OELs for both respirable and inhalable fractions. The dose-response characterisation informed by the studies used can be considered to establish a true human NOAEL for all the neurofunctional endpoints examined in the selected studies. There is no requirement for short-term exposure limits and as noted in the review by the IEH (IEH, 2004), there is no reliable biological exposure limit that can be recommended either based on a health effect or equivalence to an airborne exposure. However, research is underway to validate useful specific biomarkers of exposure to manganese, in particular for recent exposure.

It should be noted that as these recommended OELs are based on very subtle neurofunctional perturbations which represent the earliest detectable, potentially adverse changes arising from occupational exposure to manganese adherence to the proposed OELs will therefore provide protection to workers from all of the other reported effects of occupational exposure 

to manganese and its inorganic compounds. However, it is also important to highlight that

540 although the recommended OEL will provided protection to all workers, workers in different

541 fields - alloying, battery production, fertiliser production, mining, welding etc., could be

542 protected with less stringent OEL's as the valency, toxicokinetics, solubility, bioavailability of

543 different inorganic manganese based substances are not the same. Although this lends itself

544 to the concept of setting 'sector-specific' OELs, data is insufficient at the present time for the

545 derivation of pragmatic OEL's for each working group sector.

546

547 Acknowledgements

548 The authors would like to acknowledge the input of Dr Alison Searl (formerly Institute of

549 Occupational Medicine, and Mr Philip Holmes (formerly Risk and Policy Analysts Ltd.) and to

550 The IMnI for funding. The views expressed are entirely those of the authors.

551

552 


\section{References}

554 ACGIH(2013) Manganese, Elemental and Inorganic Compounds. Available at:

555 https://www.acgih.org/forms/store/ProductFormPublic/manganese-elemental-and-

556 inorganic-compounds-tlv-r-chemical-substances-7th-edition-documentation.

557

558 ATSDR (2012) Agency for Toxic Substances and Disease Registry Toxicological Profile for

559 Manganese. Available at: http://www.atsdr.cdc.gov/toxprofiles/tp151.pdf [accessed

560 February 2016].

561

562

Bast Pettersen, R., Ellingsen, D.G., Hetland, S.M., et al. (2004) Neuropsychological Function

563

in Manganese Alloy Plant Workers. International Archives of Occupational and

564 Environmental Health, 77(4), 277-287.

565

566 Berlinger, B., Náray, M., Záray, G. (2007) Comparison of different sampling heads applied for

567 investigation of welding fume. Microchemical Journal, 85, 25-30.

568

569 Berlinger, B., Náray, M., Záray, G. (2008) Distribution of metals between inhalable and

570 respirable fractions of welding fumes generated in gas metal arc welding. Science and

571 Technology of Welding and Joining, 13 (8) 721-725.

572 
573 Blond, M. \& Netterstrom, B. (2007) Neuromotor Function in a Cohort of Danish Steel Workers.

574 Neurotoxicology, 28(2), 336-344.

575

576 Blond, M., Netterstrom, B. \& Laursen, P. (2007) Cognitive Function in a Cohort of Danish Steel

577 Workers. Neurotoxicology, 28(2), 328-335.

578

579

Bolt, H., Foth, H., Hengstler, J.G. et al. (2004) Carcinogenicity categorization of chemicals-

580

new aspects to be considered in a European perspective. Toxicol Lett., 151(1) 29-41.

581

582

Bolt HM, Huici-Montagud A (2008). Strategy of the scientific committee on occupational

583

exposure limits (SCOEL) in the derivation of occupational carcinogens and mutagens. Arch

584

Toxicol 82:61-64.

585

586

Boojar M.M.A., Goodarzi,F. (2002) A longitudinal follow-up of pulmonary function and

respiratory symptoms in workers exposed to manganese. Journal of Occupational and

Environmental Medicine, 44, 282-290.

589

590 Bouchard, M., Laforest, F., Vandelac, L., et al. (2007a) Hair Manganese and Hyperactive

591

Behaviors: Pilot Study of School-Age Children Exposed through Tap Water. Environmental

592

Health Perspectives, 115(1), 122-127.

593 

Industrial Medicine, 50(11), 831-840.

597

Bouchard, M., Mergler, D., Baldwin, M., et al. (2007c) Neuropsychiatric Symptoms and Past Manganese Exposure in a Ferro-Alloy Plant.Neurotoxicology, 28(2), 290-297.

600

601

Bowler, R.M., Gocheva, V., Harris, M., et al. (2011) Prospective Study on Neurotoxic Effects in 602 Manganese-Exposed Bridge Construction Welders. Neurotoxicology, 32(5), 596-605.

603

604

Chia, S.E., Foo, S.C., Gan, S.L., Jeyaratnam, J., Tian, C.S. (1993) Neurobehavioral functions 605 among workers exposed to manganese ore. Scandinavian Journal of Work, Environment and 606 Health, 19, 264-270.

607

608 1046.

611

612

CPM Group (2011) Electrolytic Manganese Market Outlook. CPM, New York. Available at:

613 http://amydata.com/data/reports/Electrolytic_Manganese_Metal_Outlook_2011_Executive 614 Summary.pdf. 
Crump, K.S. \& Rousseau, P. (1999) Results from Eleven Years of Neurological Health 286.

619

Dankovic, D.A., B.D. Naumann, A. Maier, M.L., et al. (2015) The scientific basis of uncertainty factors used in setting occupational exposure limits. J. Occup. Envrion. Hyg. Supplement 1: S55-S68 (2015).

623

EC (2011) Recommendation from the Scientific Committee on Occupational Exposure Limits for manganese and inorganic manganese compounds. SCOEL/SUM/127.

EC Employment, Social Affairs and Inclusion (2013) Methodology for the Derivation of Occupational Exposure Limits. Scientific Committee on Occupational Exposure Limits (SCOEL) Key Documentation (version 7).

Ellingsen, D.G, Hetland, S.M, Thomassen, Y. (2003) Manganese air exposure assessment and biological monitoring in the manganese alloy production industry. J. Environ. Monit. 5, 4-90. 
637 Gibbs, J.P., Crump, K.S., Houck, D.P., et al. (1999) Focused Medical Surveillance: A Search for 638 Subclinical Movement Disorders in a Cohort of U.S. Workers Exposed to Low Levels of 639 Manganese Dust. Neurotoxicology, 20(2-3), 299-313.

640

641 Gil, F., Hernández, A.F., Márquez, C., et al. (2011) Biomonitorization of Cadmium,

642 Chromium, Manganese, Nickel and Lead in Whole Blood, Urine, Axillary Hair and Saliva in an 643 Occupationally Exposed Population. Science of the Total Environment, 409(6), 1172-1180.

Harris, M.K., Ewing, W.M., Longo, W., et al. (2005) Manganese Exposures during Shielded Metal Arc Welding (SMAW) in an Enclosed Space. Journal of Occupational and Environmental Hygiene,2(8), 375-382.

648

649 HC (2008) Human Health Risk Assessment for Inhaled Manganese Draft Water, Air \& Climate Change Bureau Health Canada, March, 2008.

651

652 IEH (2004) Institute for Environment and Heath. Occupational exposure limits: Criteria document for manganese and inorganic manganese compounds. IEH Web Report W17.

654 Available at:

655 http://www.iehconsulting.co.uk/IEH Consulting/IEHCPubs/HumExpRiskAssess/w17.pdf 656 [accessed Jume2016]. 
658

659

660

661

662

663

664

665

666

667

668

669

670

671

672

673

674

675

676

677

678

679

Johnsen, H.L., Hetland, S.M., Benth, J.Š., et al. (2010) Dust Exposure Assessed by a Job

Exposure Matrix is Associated with Increased Annual Decline in FEV1: A 5-Year Prospective

Study of Employees in Norwegian Smelters. American Journal of Respiratory and Critical

Care Medicine, 181(11), 1234-1240.

Keane, M., Stone, S., Chen, B. (2010) Welding Fumes from Stainless Steel Gas Metal Arc

Processes Contain Multiple Manganese Chemical Species. Journal of Environmental Monitoring, 12(5), 1133-1140.

Laohaudomchok, W., Lin, X., Herrick, R.F., et al. (2011a) Neuropsychological Effects of LowLevel Manganese Exposure in Welders. Neurotoxicology, 32(2), 171-179.

Lauwerys, R., Roels, H., Genet, P., et al. (1985) Fertility of Male Workers Exposed to Mercury Vapor Or to Manganese Dust: A Questionnaire Study. American Journal of Industrial Medicine, 7(2), 171-176.

Lehnert, M., Pesch, B., Lotz, A., et al. (2012) Exposure to Inhalable, Respirable, and Ultrafine Particles in Welding Fume. Annals of Occupational Hygiene, 56(5), 557-567.

Lucchini, R., Apostoli, P., Perrone, C., et al. (1999) Long-Term Exposure to "Low Levels" of Manganese Oxides and Neurofunctional Changes in Ferroalloy Workers. Neurotoxicology, 20(2-3), 287-297. 
Mergler, D., Huel, G., Bowler, R., et al. (1994) Nervous System Dysfunction among Workers with Long-Term Exposure to Manganese. Environmental Research,64(2), 151-180.

683

Meyer-Baron, M., Knapp, G., Schaper, M., et al. (2009) Performance Alterations Associated 685 with Occupational Exposure to Manganese--a Meta-Analysis. Neurotoxicology, 30(4), 487496.

Meyer-Baron, M., Schaper, M., Knapp, G.et al. (2013) The neurobehavioral impact of manganese: Results and challenges obtained by a meta-analysis of individual participant data. Neurotoxicology, 36, 1-9.

691

Michalke, B., Halbach, S. \& Nischwitz, V. (2007) Speciation and Toxicological Relevance of Manganese in Humans. Journal of Environmental Monitoring, 9(7), 650-656.

694

695

Myers, J.E., teWaterNaude, J.M., Abie Zogoe, H.B., Fourie, M., Naik, I., Theodorou, P., Tassell, H., Daya, A.,Thompson, M. (2002) Two Phase Longitudinal or Prospective Study of the Nervous System Effects of Occupational Environmental Exposures on Mineworkers or Processing Plant Workers at Two Manganese Mines, Capetown, South Africa. Safety in Mines Research Advisory Committee (SIMRAC). 
701

702

703

704

705

706

707

708

709

710

711

712

713

714

715

716

717

718

719

720

721

722

Myers, J.E., Thompson, M.L., Ramushu, S., et al. (2003a) The Nervous System Effects of

Occupational Exposure on Workers in a South African Manganese Smelter. Neurotoxicology, 24(6), 885-894.

Myers, J.E., teWaterNaude, J., Fourie, M., et al. (2003b) Nervous System Effects of

Occupational Manganese Exposure on South African Manganese Mineworkers.

Neurotoxicology, 24(4-5), 649-656.

Pearson, G.F. \& Greenway, G.M. (2005) Recent Developments in Manganese Speciation.

TrAC - Trends in Analytical Chemistry,24(9), 803-809.

Roels, H., Lauwerys, R., Genet, P., Sarhan, M.J., de Fays, M., Hanotiau, I., Buchet, J.-P. (1987)

Relationship between external and internal parameters of exposure to manganese in

workers from a manganese oxide and salt producing plant. American Journal of Industrial

Medicine, 11,297-305

Roels, H., Ghyselen, P., Buchet, J., et al. (1992) Assessment of the Permissible Exposure Level to Manganese in Workers Exposed to Manganese Dioxide Dust. British Journal of Industrial Medicine, 49(1), 25-34.

Ross, J.A.S., Semple, S., Duffin, R., et al. (2009) Characterisation of Fume from Hyperbaric Welding Operations. Journal of Physics: Conference Series, 151(1), 012042. 
Sjögren, B., Iregren, A., Frech, W., et al. (1996) Effects on the nervous system among welders exposed to aluminium and manganese. Occup Environ Med., 53, 32-40.

Spreen, O., Strauss, E. A compendium of neuropsychological tests: administration, norms, and commentary. New York: Oxford University Press, 2006.

Unlu, I., Kesici, G.G., Basturk, A., et al. (2014) A comparison of the effects of solvent and noise exposure on hearing, together and separately. Noise and Health, 16, 410-415.

Wang, X., Yang, Y., Wang, X. et al. (2006) The effect of occupational exposure to metals on the nervous system function in welders. J Occup Health 48(2) 100-6.

Wastensson, G., Sallsten, G., Bast-Pettersen, R., et al. (2011) Neuromotor Function in Ship Welders After Cessation of Manganese Exposure. International Archives of Occupational and Environmental Health, 85(6), 703-713.

Young, T., Myers, J.E. \& Thompson, M.L. (2005) The Nervous System Effects of Occupational Exposure to Manganese--Measured as Respirable Dust--in a South African Manganese Smelter. Neurotoxicology,26(6), 993-1000.

Yuan, H., He, S., He, M., et al. (2006) A comprehensive study on neurobehavior, neurotransmitters and lymphocyte subsets alteration of Chinese manganese 

welding workers. Life Sci., 78(12) 1324-8.

746

747 Zheng, W., Fu, S.X., Dydak, U., et al. (2011) Biomarkers of Manganese Intoxication.

748 Neurotoxicology, 32(1), 1-8.

749

750 


\section{Appendix A - Literature search strategy}

\section{Web of Science}

753

TOPIC ("BaMnO4" OR "KMnO4" OR "FeMn" OR "Mn2O3" OR "Mn3O4" OR "Mn3O7" OR "Mn5O8" OR "Mn(NO3)2" OR "Mn(SO4)2" OR "Mn2(SO4)3" OR "MnCl2" OR "MnO" OR "MnO2" OR "MnSO4" OR "Na3MnO4" OR "SiMn" OR siliconmanganese OR "manganous salt*" OR braunite OR cianciulliite OR hausmannite OR polianite OR pyrochroite OR pyrolusite OR ramsdellite) AND TOPIC (toxic* OR exposure* OR manganism OR parkinson* OR poison* OR teratogen* OR mutagen* OR carcinogen* OR genotox* OR neurotox* OR repro*) AND TOPIC (worker* OR workplace OR occupation*)

\section{Scopus}

TITLE-ABS-KEY (\{BaMnO4\} OR \{KMnO4\} OR \{FeMn\} OR \{Mn2O3\} OR \{Mn3O4\} OR $\{\mathrm{Mn} 307\}$ OR \{ Mn5O8\} OR $\{\mathrm{Mn}(\mathrm{NO} 3) 2\}$ OR $\{\mathrm{Mn}(\mathrm{SO} 4) 2\}$ OR $\{\mathrm{Mn} 2(\mathrm{SO} 4) 3\}$ OR $\{\mathrm{MnCl} 2\}$ OR $\{\mathrm{MnO}\}$ OR $\{\mathrm{MnO} 2\}$ OR \{MnSO4\} OR \{Na3MnO4\} OR \{SiMn\} OR siliconmanganese OR \{manganous salt $\}$ OR \{manganous salts\} OR braunite OR cianciulliite OR hausmannite OR polianite OR pyrochroite OR pyrolusite OR ramsdellite) AND TITLE-ABS-KEY (toxic* OR exposure* OR manganism OR parkinson* OR poison* OR teratogen* OR mutagen* OR carcinogen* OR genotox* OR neurotox* OR repro*) AND TITLE-ABSKEY (worker* OR workplace OR occupation*) 